\title{
"Data Hegemony": Reflections for the Application and Development Direction of Metaverse Technology in Urban Design based on Digital
}

\author{
Qinyu Feng*, Renjie Cai \\ The University of Sheffield, Sheffield S10 2TT, the United Kingdom \\ *Corresponding author: Qinyu Feng, qfeng7@sheffield.ac.uk
}

\begin{abstract}
This paper is based on the phenomenon of Tittytainment and big data control. It discusses the ways in which working youths live and work in their large suburban communities in Beijing as well as their leisure and entertainment activities. Then develops a problem statement and research questions. In addition, the project explores this reality phenomenon dialectically through the analysis and speculation of the new virtual reality technology "Metaverse." Based on a critical design approach, the phenomenon is explored through a detailed description and examination of reality, before critically suggesting the possibility of future social control by big data companies through the "metaverse" space. Furthermore, this paper alerts to the neoliberalism that dominates globalization through anti-utopian expressions, waking up young people who are compromised by big data control and addicted to Tittytainment.
\end{abstract}

Keywords: Urban design; Metaverse technology; Big data; Neoliberalism

Publication date: November 2021; Online publication: November 30, 2021

\section{Introduction}

Based on the new virtual reality technology "Metaverse," this paper focuses on the control of big data and entertainment control in society, and critically projects the feasibility of new entertainment spaces in the community of the future. In Beijing, large suburban communities are dominated by a large number of university students and migrant workers, who are the city's main workforce, a large consumer population, and a marginalized population. In Beijing, rising housing prices are pushing young people increasingly far away from the city center, with distances to live and work becoming more remote, fewer public spaces for cheap youth, and increasing social pressure to survive. This pressure to survive has led the "marginalized" to choose to numb themselves with cheap and comforting entertainment and products full of sensual stimulation (video games, virtual social networking, pornography, mass entertainment such as soap operas and reality shows). At the same time, big data companies (Alibaba, Tencent, etc.) have started to export entertainment products to young people through big data analysis, while acquiring massive amounts of related entertainment industries, products and companies to achieve a monopoly on entertainment. These entertainment products abound in every free time of young people and can be used to spend time in any place, although it brings them great pleasure.

This paper examines how big data businesses use data control and entertainment monopolies to manipulate society and individuals in order to establish digital hegemony. How big data is used to manipulate society digitally, how entertainment orientation is used to control society, how the new digital technological "Metaverse" integrates a monopoly on entertainment products, and how people will resist or submit to the new entertainment spaces created by large corporations. It is based on the Tittytainment 
Theory and Pareto Principle neoliberal theories from 1995.

\section{Neoliberal urbanism on digital hegemony}

De-industrialization, re-industrialization, post-Fordism, internationalization, urban entrepreneurialism, and other terms have been used to define neoliberal urbanism (Figure 1), which has been endorsed and pushed by a generation of academics ${ }^{[1]}$. The neoliberal goal also includes decentralizing government from the federal to local levels, reducing macro-control, and promoting private enterprise and the free market.

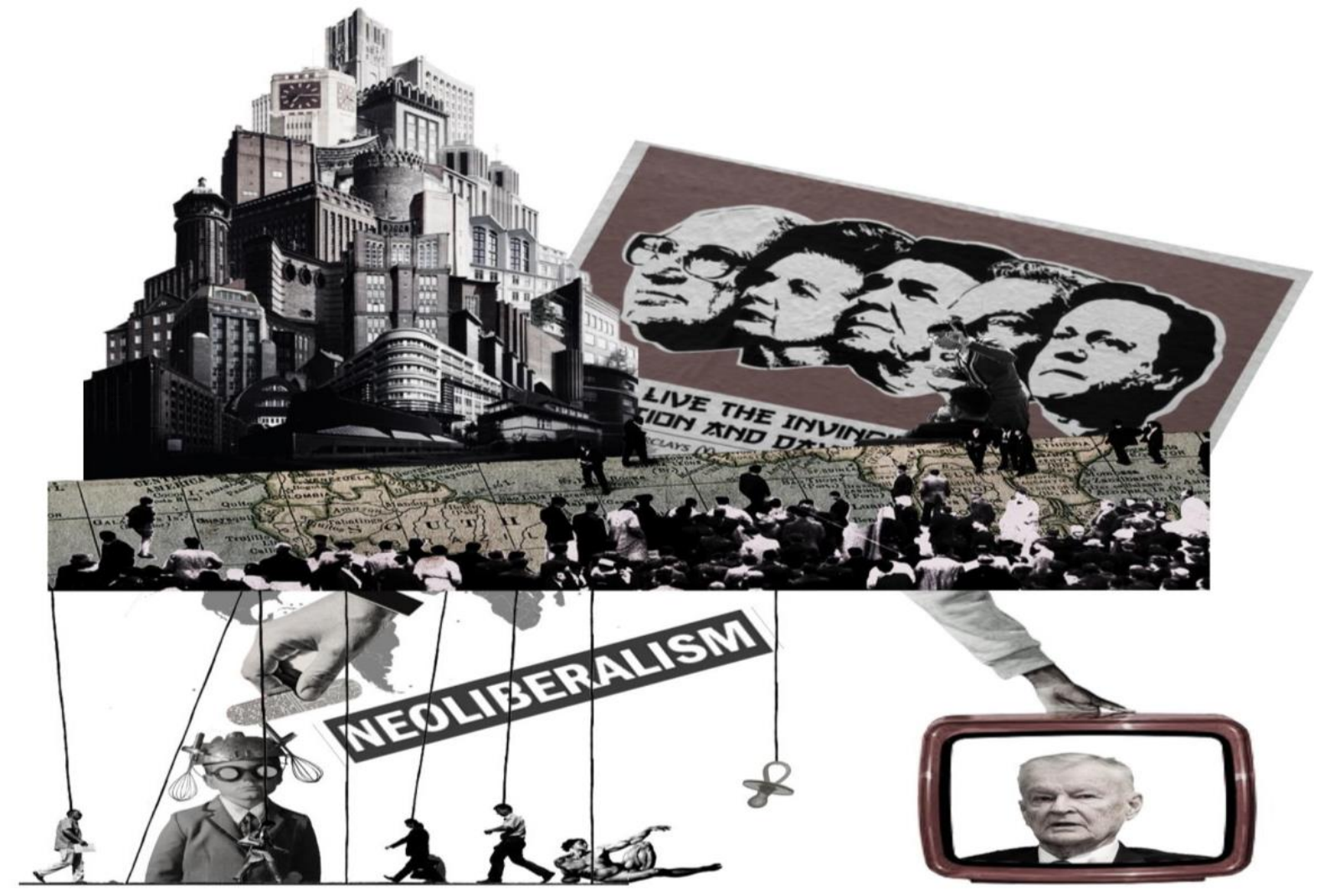

Figure 1. Lies of Neoliberalism

\subsection{Neoliberalism and the Two-Eight Principle}

\subsubsection{Two-Eight Principle}

Today's urban crisis, with poverty and inequality, unemployment and underemployment, inadequate and unaffordable housing and public transport, traffic congestion, pollution of cities, etc., is largely due to the fact that neoliberalism has left governments without sufficient funds and powers to ensure that cities function and protect the underclass ${ }^{[2]}$. The economic and political elite agreed at the historic "State of the World Forum" in September 1995 that globalization would generate a big problem - the gap between rich and poor ${ }^{[3]}$. The world would be a place where $20 \%$ of the population controlled $80 \%$ of the resources and the remaining $80 \%$ were "marginalized" (Figure 2).

As a result, rather of solving contemporary capitalism's political and economic crisis trends, neoliberalism has deepened social fragmentation, expanded the wealth gap, and shattered social solidarity ${ }^{[4]}$. In developing countries, the development of the real estate market as a result of neoliberalism has caused the ratio of housing expenditure to per capita income to soar, leading to a worsening housing crisis.

Brzezinski, the former US National Security Advisor, said that no one has the power to change the future "Two-Eight Phenomenon" and that there is only one way to relieve the energy and discontent of the "marginalised" [6], and that is to introduce a new strategy of Tittytainment, which means putting a "pacifier" 
in the mouth of the $80 \%$.

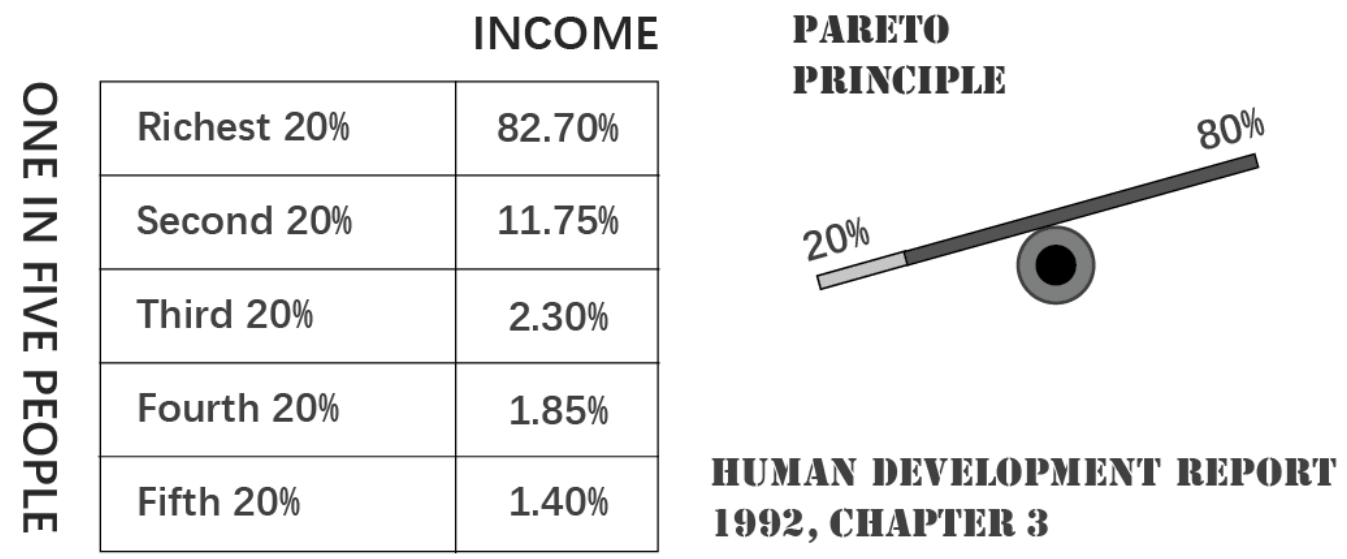

Figure 2. The two-eight phenomenon of social wealth distribution, World Bank and World development report 1992: Development and the environment ${ }^{[5]}$.

\subsubsection{Two-Eight Principle and Tittytainment}

Tittytainment is a term describing the propaganda designed to protect the capitalist and neo-liberal principles that govern globalization. The essence of the two-eight principle and tittytainment is to protect economic globalization and neoliberalism ${ }^{[6]}$, while ensuring the class status of the elite $(20 \%)$.

Amusing Ourselves to Death, written by Postman, presents us with a scenario in which our politics, religion, journalism, sport, education and business are willingly made subservient to entertainment, without complaint, even silently, with the result that we have become a species of entertainment to death. In Technopoly: The Surrender of Culture to Technology, Postman also refers to the computer as the "quintessential, unparalleled, near-perfect" technology of the technological monopoly. It has established sovereignty over all areas of human experience ${ }^{[7]}$.

To some extent the tittytainment is not a conspiracy theory, it is a necessary trend resulting from technological development. Culture bowing to technology. In a survey of young people in Beijing (Figure 3), it was found that in a high-pressure environment, increasing young people are actively or passively choosing to numb themselves with vulgar, fast and exciting forms of entertainment, "seeking pleasure to escape pain, hope to escape fear, identity to escape rejection."

\subsection{Tittytainment and big data}

Behind the Tittytainment and Entertainment to Death is the monopoly of the big companies on media and entertainment, with the control of big data calculation engines.

\subsubsection{Digital entertainment}

The datafication of media and entertainment is the new megatrend. Large internet companies and media companies are integrating or collaborating. Media organizations around the world are using big data in an effort to compete in a globalized media market and to better tailor content for local audiences ${ }^{[8]}$. The convergence of big data and media entertainment has created new centers of power - not based on control of content, but on control of big data. With the help of big data calculations, these companies can tend to launch products with greater profit and gain greater efficiency ${ }^{[9]}$. 


\subsubsection{Ethics of big data}

However, in the neoliberal context of a lack of government regulation and control, large internet companies and media outlets are only concerned with data traffic and profits, not with the content of their products or the ethics and values of society ${ }^{[10]}$. With no relevant control, on the one hand, large companies use their absolute advantage over big data to constantly acquire new Internet companies, forming an absolute technological monopoly, while constantly upgrading their big data computing power to obtain more data from citizens. On the other hand, big data guides the products and content orientation of media and entertainment companies and the content becomes even more vulgarized ${ }^{[11]}$. Moreover, the vast majority of the public has no right to privacy, information, or participation in Big Data as the power of the Internet company giants, and the public is left to passively accept the rules of the digital world. As a result, most of the big data frameworks are clearly classist and biased, representing the profits and positions of the internet giants.

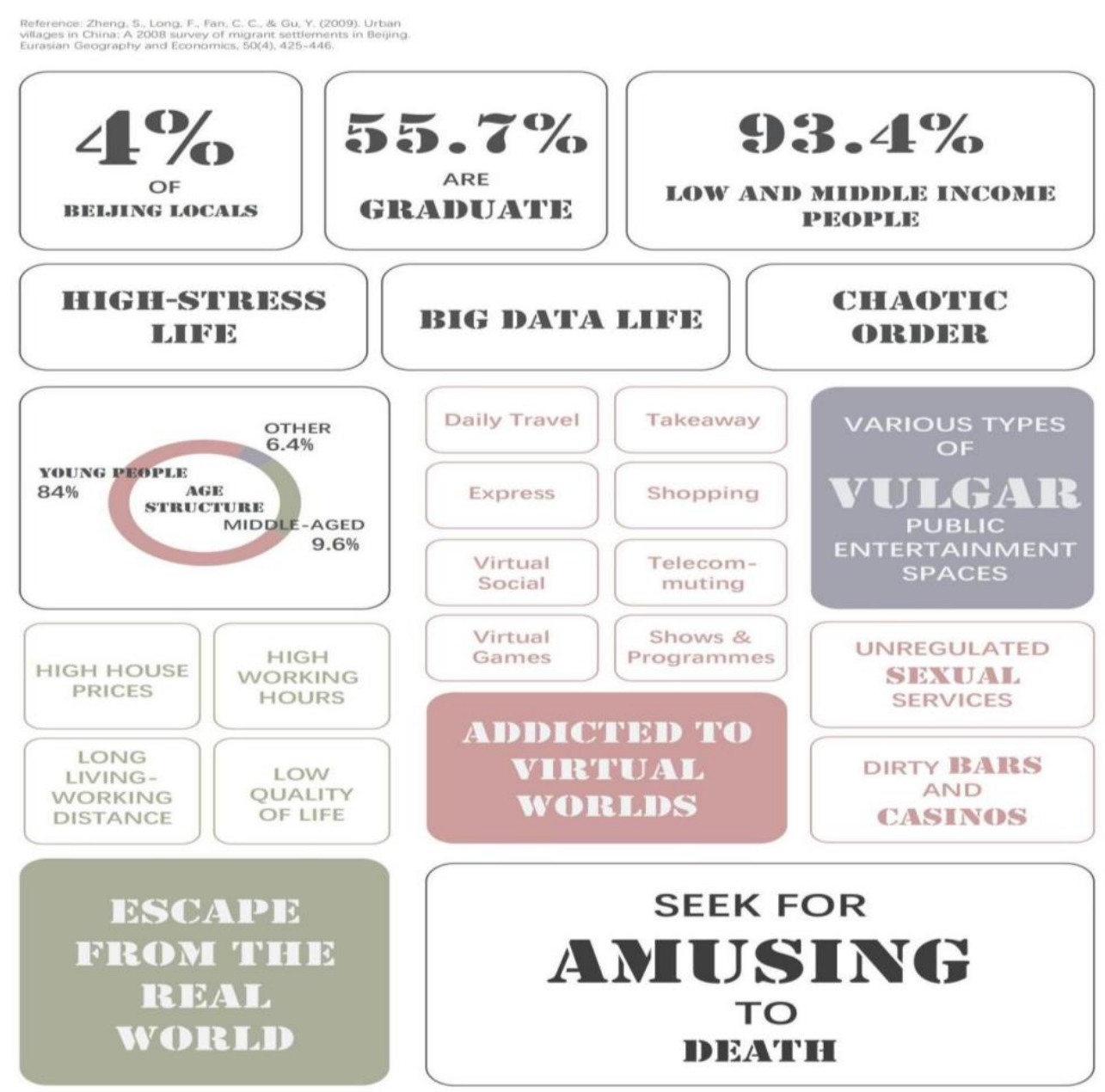

Figure 3. Beijing Urban Village Entertainment Survey

\section{Metaverse technology}

Metaverse, the term was coined in Neal Stephenson's 1992 science fiction novel Snow Crash, in which humans, as avatars, interact with each other and software agents in a three-dimensional space that uses the metaphor of the real world. The Metaverse is a collective virtual shared space made up of a fusion of virtually augmented physical reality and physically sustained virtual space, encompassing the sum of all virtual worlds, augmented reality and the internet ${ }^{[12]}$. Stephenson uses this term to describe a successor to the virtual reality-based Internet. It is a platform that can coordinate all media and electronic entertainment. 
Today's internet giants are constantly innovating technology to make this vision a reality. Therefore, the application and development of mixed reality technologies will be a new challenge in future urban design projects.

On 23 June 2003, Second Life, the poster child for online virtual worlds, was launched in San Francisco. Users of Second Life, also known as residents, create their own virtual representations, called avatars, and are able to interact with locations, objects and other avatars ${ }^{[13]}$. Starting with the release of Second Life, the door has been opened to the virtual world, which is invading the real world. The Internet giants are continuing to innovate technology to realize the vision of the metaverse. The foundation of the metaverse is Big Data, which, as a digital phenomenon, allows the collection and use of vast amounts of data from people and machines. This data is characterized by its volume, variety, speed, authenticity, variability and complexity ${ }^{[14]}$. These companies maximize the productivity and efficiency of service and product delivery by rapidly capturing big data, analyzing and exploiting the information, with media and entertainment companies reaping the biggest profits.

\subsection{Big data monopolies}

The big data software (official software related to Alipay) in China, which is divided into four categories and 15 sub-categories, with a total of over 678 related software (APP), basically covering all aspects (Figure 4). The history of the Internet is a history of big companies pouring all their efforts into developing computing power, developing artificial intelligence algorithms and stealing ideas from people's brains before implanting them.

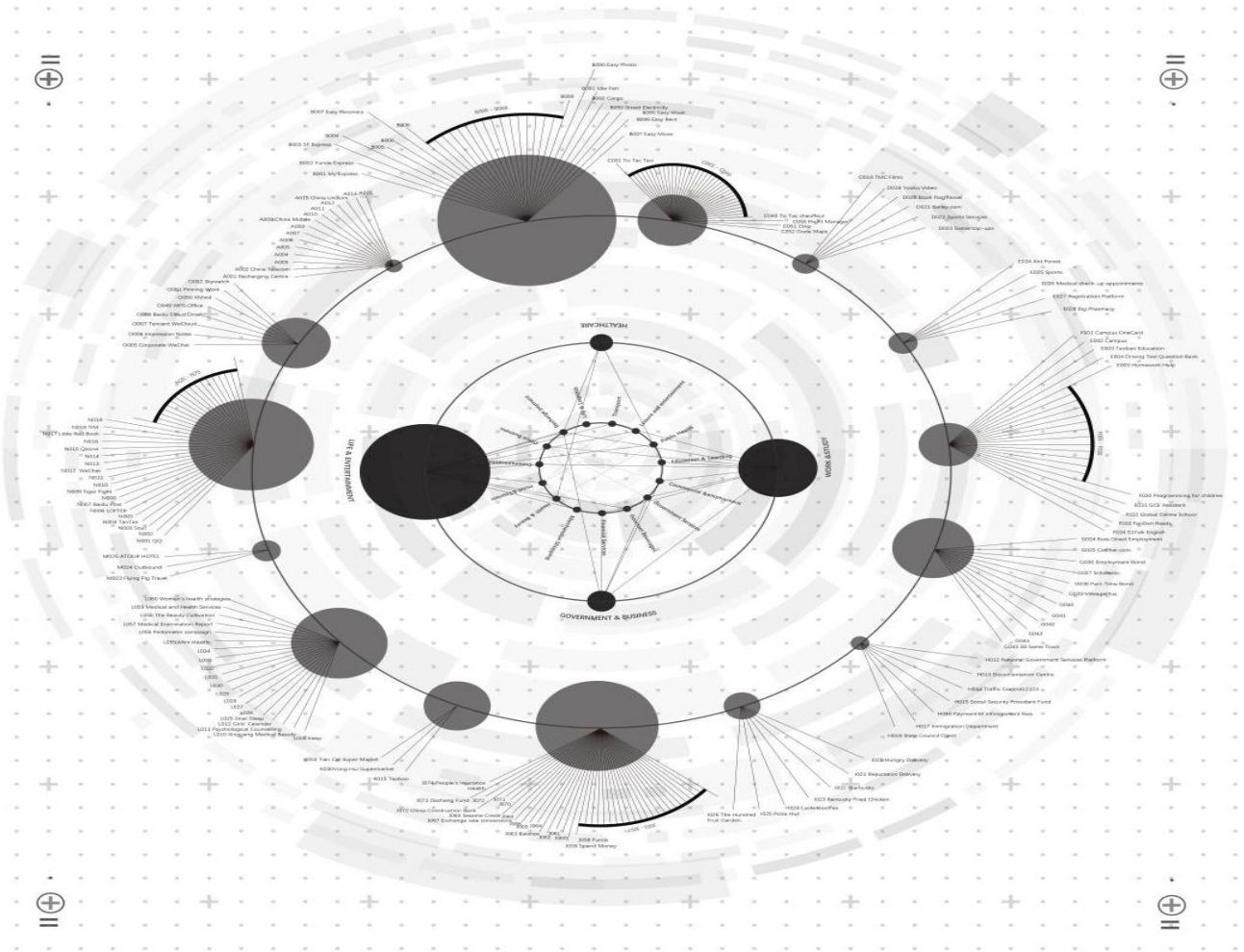

Figure 4. Big Data Software Network (official software related to Alipay)

These large companies will understand our needs better than we do ourselves (Figure 5), not only can they read our minds, offer us better services and products and profit from us, but they can also influence our minds, change our values and limit and change our behavior without us realizing it. 


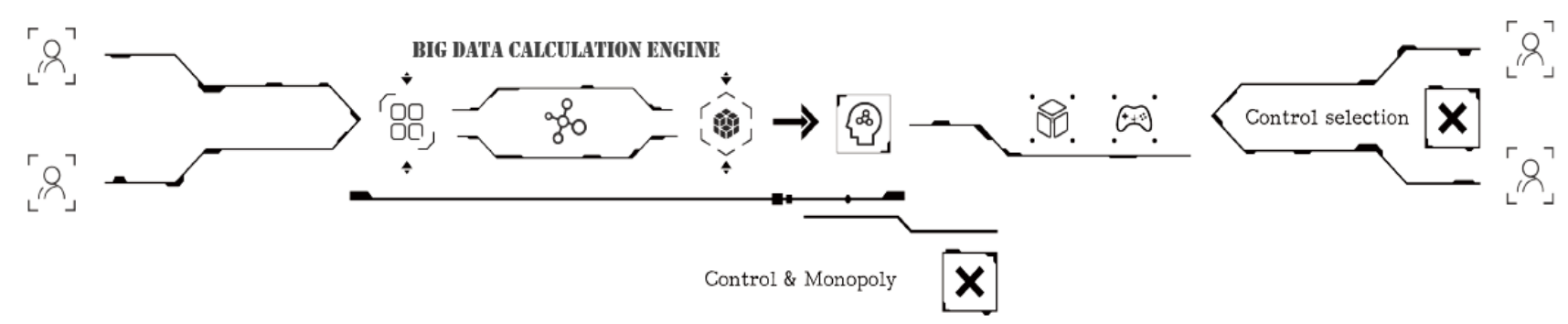

Figure 5. Big Data Calculation Engine

\subsection{Technology and entertainment monopolies}

The Metaverse is a collective virtual shared space, a fusion of virtually enhanced physical reality and physically persistent virtual space, encompassing the sum of all virtual worlds, augmented reality and the internet (Figure 6). Through Metaverse technology, big companies use big data to achieve an absolute monopoly and control over virtual worlds and entertainment orientation (Figure 7).

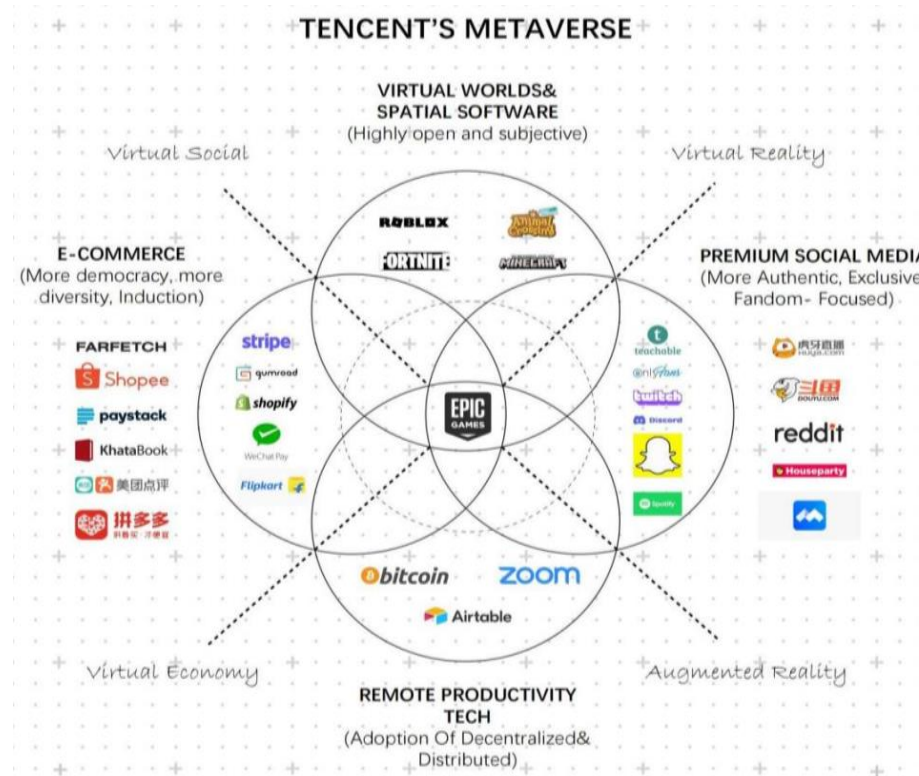

Figure 6. Tencent's Ambitions for The Metaverse ${ }^{[15]}$

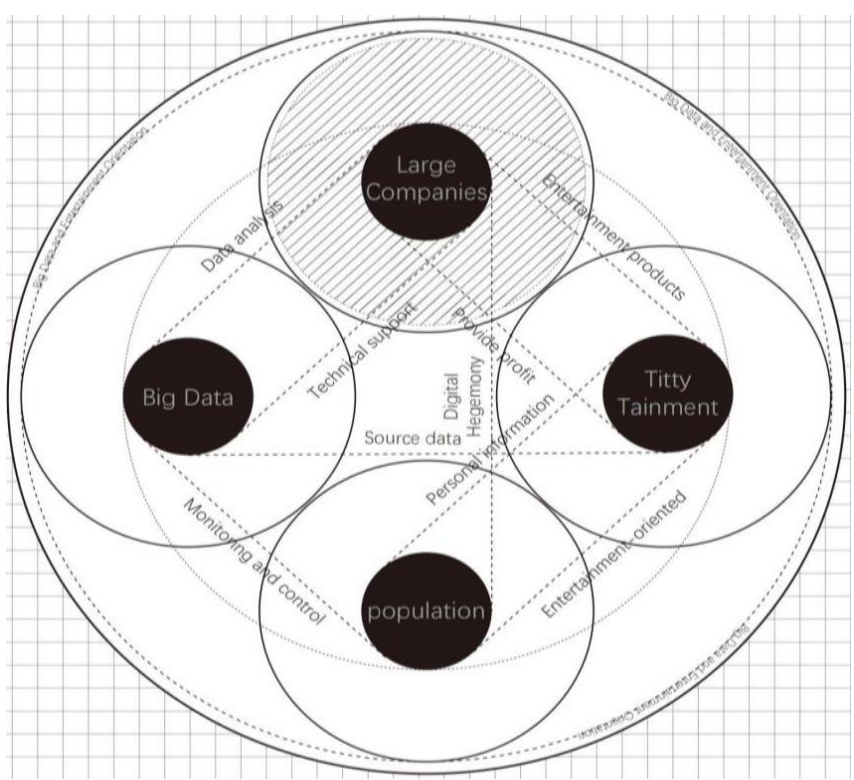

Figure 7. Big Data and Entertainment Orientation

Apart from WeChat, Tencent has made almost no research on any product or technology. This includes the virtual economy, social entertainment, VR technology, AR technology, office learning and more, with over nearly 30 acquisitions and investments in Internet companies. This huge company has acquired a large number of technology-based companies. There is no doubt that it controls almost all aspects of entertainment orientation.

\section{Metaverse and urban communities}

Realising speculation about future communities requires observation of existing communities. The main problems underlying this observation can be divided into three areas: Work and life, data and identity, and entertainment and space.

\subsection{Big data and urban communities}

Beijing Pixel is located in the middle of the 5th to 6th ring road in the Chaoyang district of Beijing. The entire community is a commercial and residential property, with a population of approximately 70,000 people living in the whole community, possibly more. Ninety-three per cent of the people living here are 
low- and middle-income migrant workers. The high pressure of work and the low standard of living have led these young people to choose cheap and vulgar entertainment to stimulate and numb themselves. Small bars, sex establishments, internet cafes, nightclubs and casinos are hidden among neighborhood (Figure 8). The internet, games, celebrity hunting and reality shows are the main forms of entertainment. The necessities of life (Figure 9) such as takeaway, delivery, shopping, internet and media entertainment are almost monopolized by large corporations.

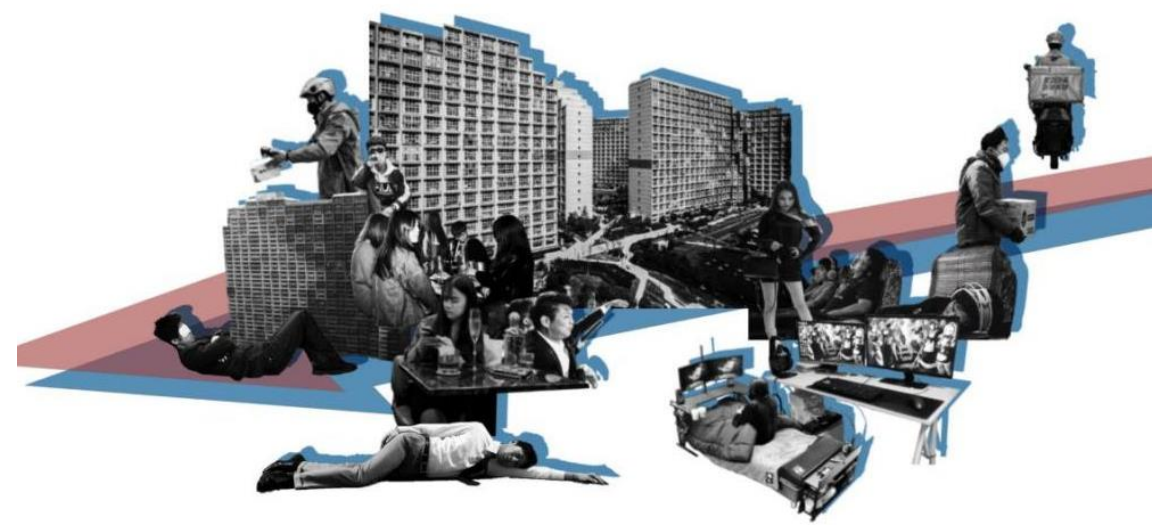

Figure 8. A Life without Choice

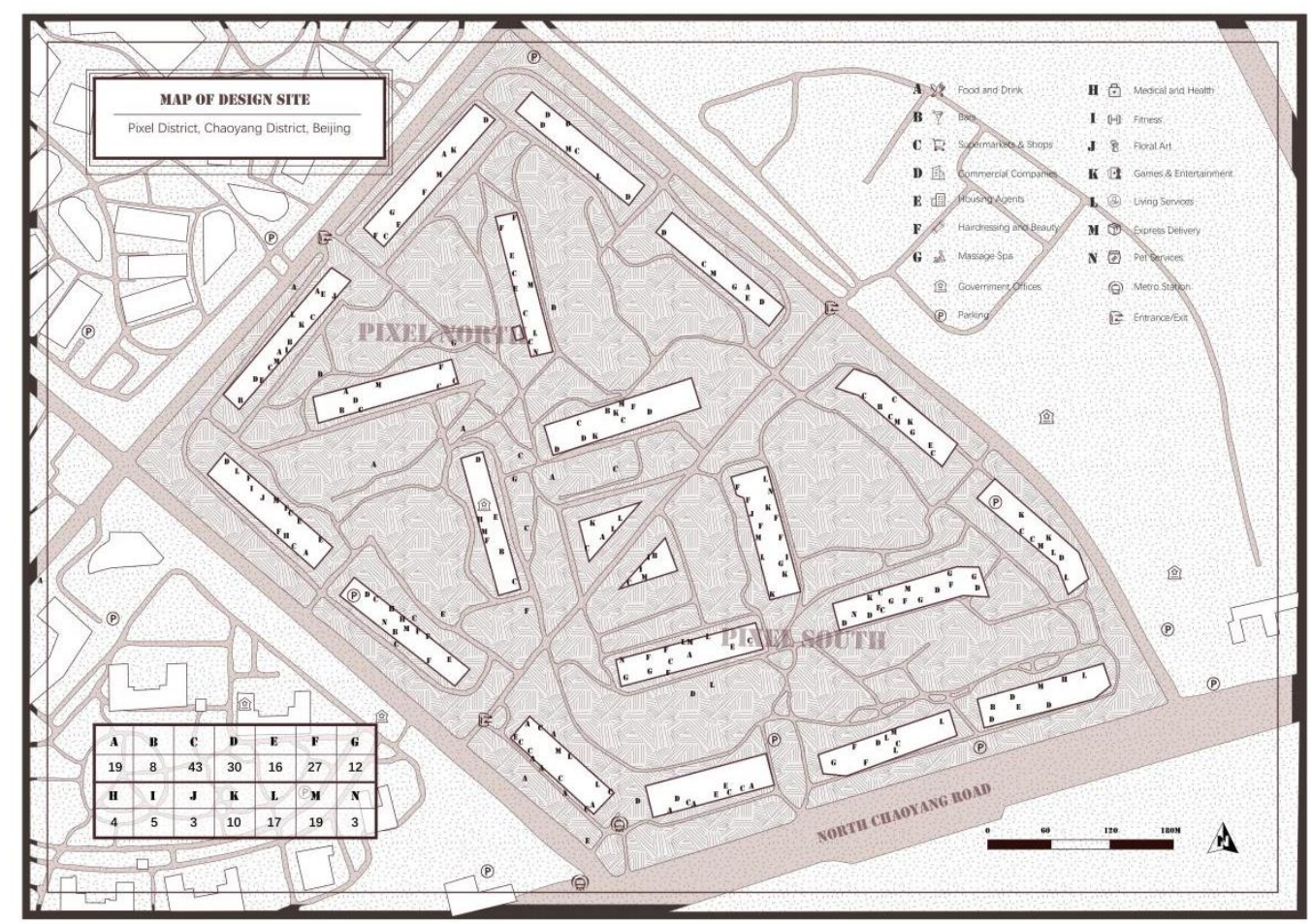

Figure 9. Site Function Mapping

Big data monitoring of community residents by large companies has permeated all aspects of the lives and work of young people, personal identity data is structured, and while personal information datafication has become a powerful phenomenon and big data calculations are capable of meeting a large amount of recreational demand ability, there is no orientation towards providing healthy and quality recreational content. One aspect of the community lacks adequate space and infrastructure, as well as a lack of positive entertainment values to guide it. More importantly, big companies will gradually dominate the community 
entertainment culture by perfecting data computing and vulgar and stimulating entertainment will become the mainstream demand in the future, corrupting and destroying the willpower of young people.

\subsection{Manifesto of metaverse}

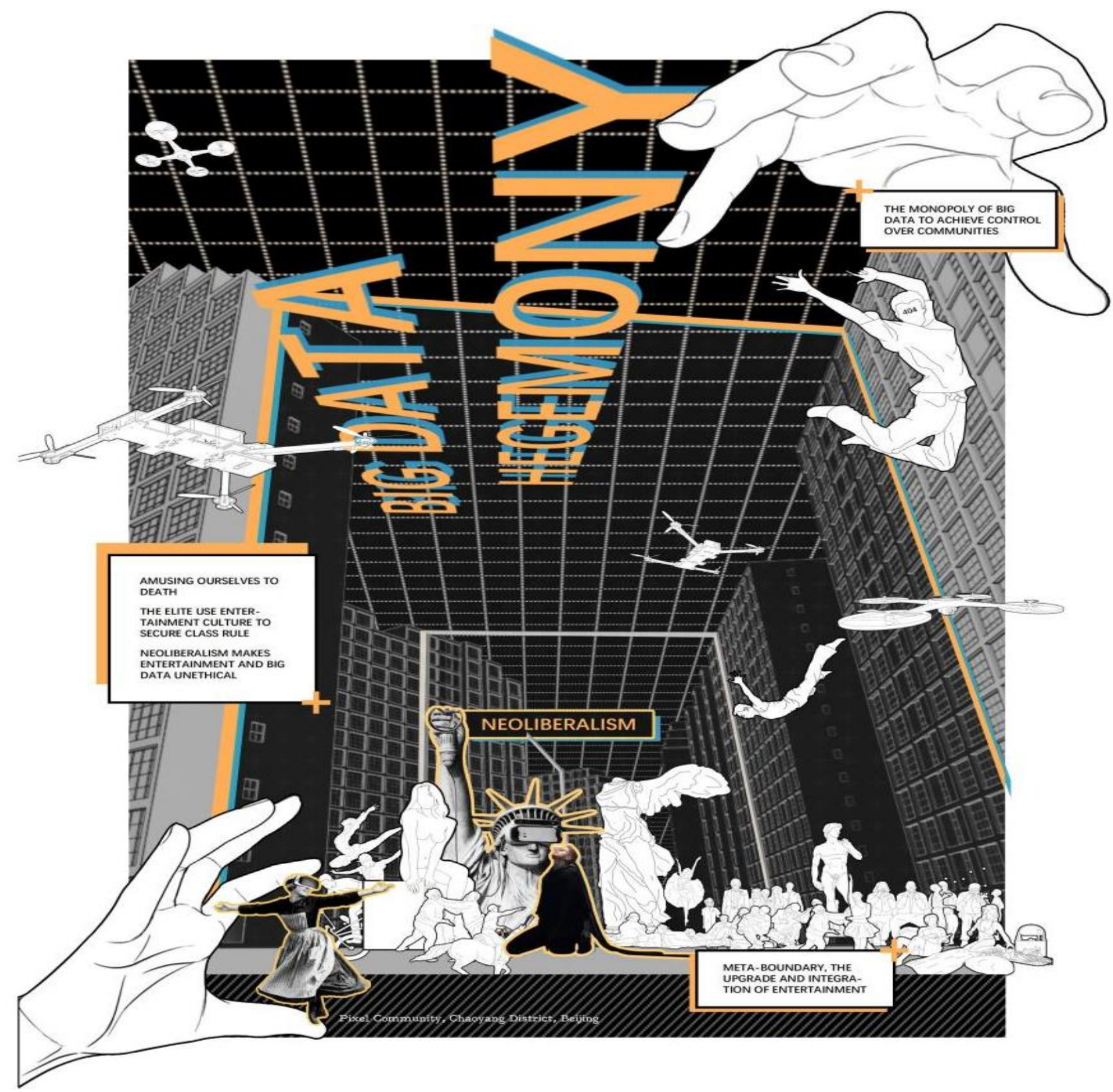

Figure 10. Thinking about digital technology and entertainment orientation

Discussing the economic development of virtual worlds and entertainment culture brought about by technological innovation deserves attention at a time when the rapid development of big data computing technology and internet technology is being noticed, but at the same time the ethical orientation of big data companies and big data entertainment needs more attention. From the perspective of urban designers and urban practitioners, we need to think forward about how big data manipulates society digitally, how entertainment orientation is used to control society, how the new digital technology "Metaverse" integrates the monopoly of entertainment products, and to think about how individuals will resist or submit to the new entertainment spaces created by big companies. 


\subsection{Metaverse in the future}

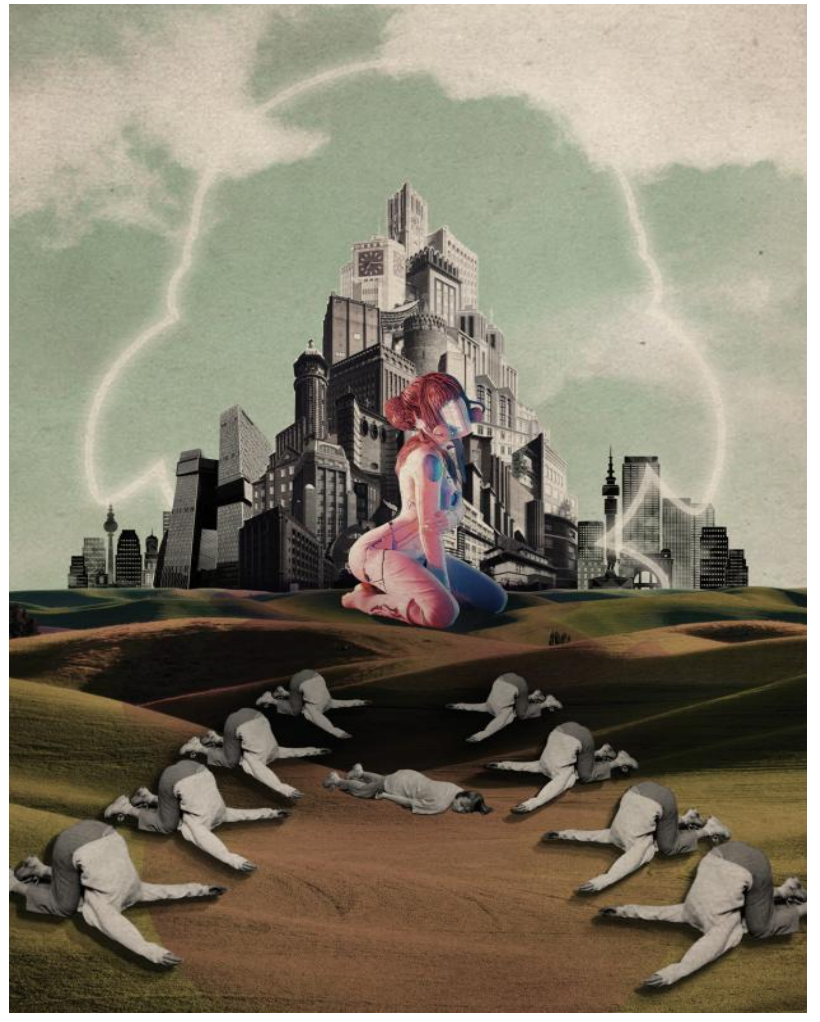

Figure 11. Entertainment Empire

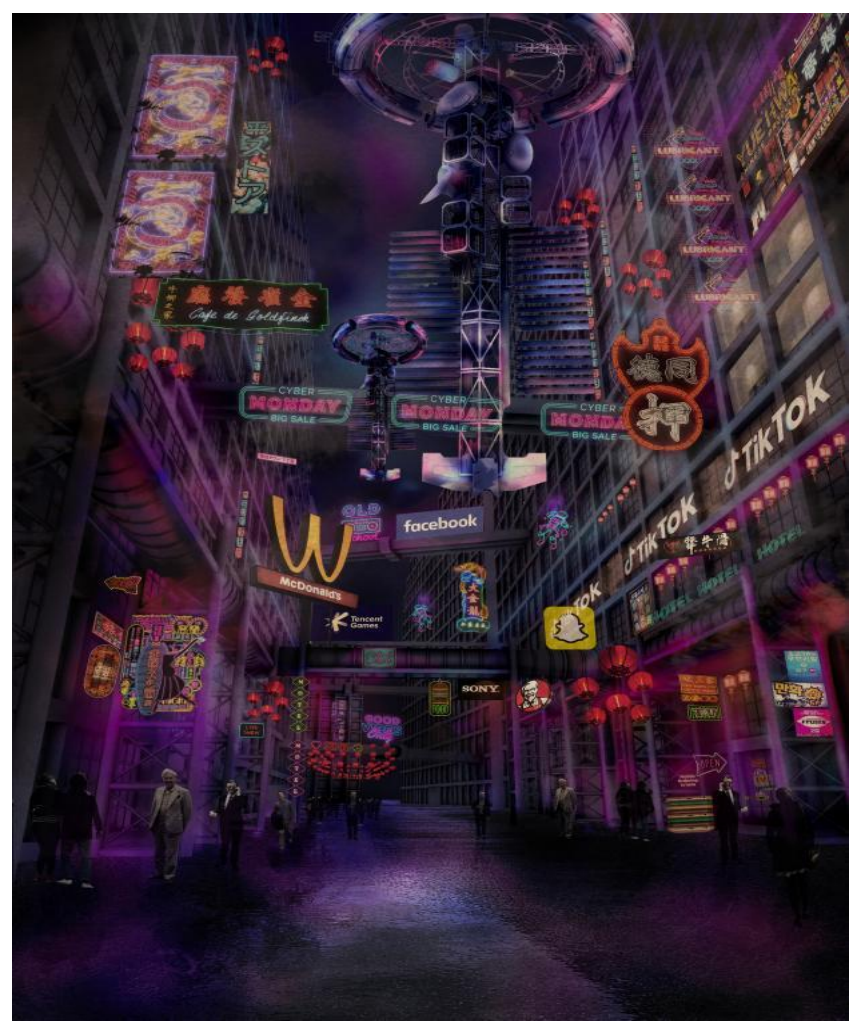

Figure 12. Digital Hegemony

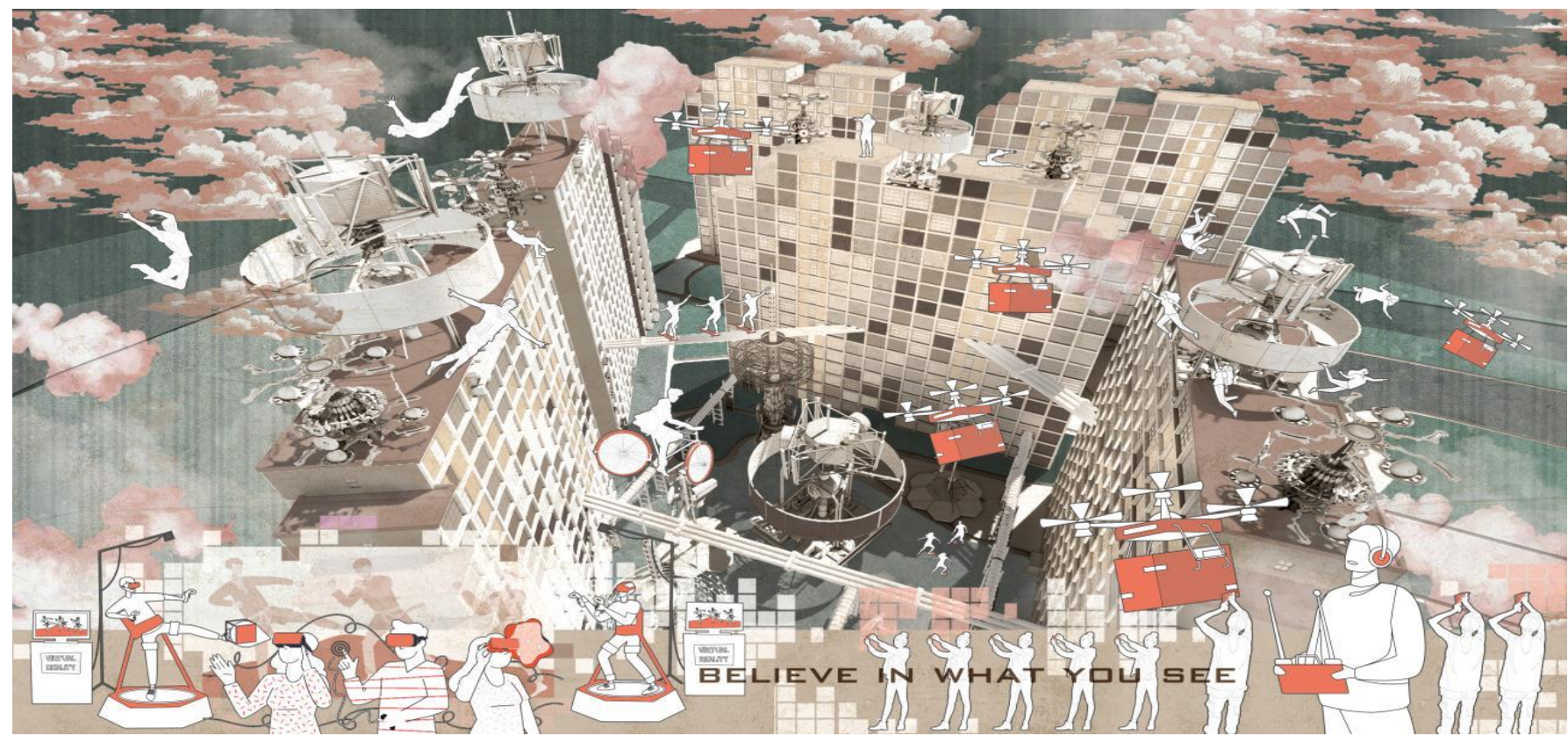

Figure 13. Communities of the Future

\section{Conclusion}

In conclusion, the topic of "Digital Hegemony" is a unique and complex one. It involves theories not only related to urban design. It also involves knowledge from economic, political, social, digital and other subjects.

In fact that it makes more sense to ask a poignant question and challenge rather than a conventional formal project. The whole design is an expression of a new virtual reality model of living in the future, 
which is of course based on particular communities and particular people. However, the heavily exaggerated, even frightening digital facilities in the design expression are a warning against the neoliberalism that leads globalization through an anti-utopian expression, a questioning of the ethics of big data entertainment, and a questioning of the constant monopolization of technology and industry by big data companies to wake up young people who are damaged by the control of big data and addicted to Tittytainment.

\section{Disclosure statement}

The author declares no conflict of interest.

\section{References}

[1] Miraftab F, Wilson D, Salo K, 2015, Cities and Inequalities in a Global and Neoliberal World. Routledge.

[2] Brenner N, Theodore N, 2005, Neoliberalism and the Urban Condition. City, 9(1): 101-107.

[3] Brian K, 2015, OECD Insights Income Inequality the Gap between Rich and Poor: The Gap between Rich and Poor. OECD Publishing.

[4] Berry M, 2014, Neoliberalism and the City: or the Failure of Market Fundamentalism. Housing, Theory and Society, 31(1): 1-18.

[5] World Bank, 1992, World development report 1992: Development and the environment. The World Bank.

[6] Martin P, Schumann H, 1997, Die Globalisierungsfalle, Der Angriff auf Demokratie und Wohlstand. Ich. Die Psychozeitung, Berlin (UVA), 8(2): 8-11.

[7] Postman N, 2011, Technopoly: The Surrender of Culture to Technology. Vintage.

[8] Arsenault AH, 2017, The Datafication of Media: Big Data and the Media Industries. International Journal of Media \& Cultural Politics, 13(1-2), 7-24.

[9] Hallur GG, Prabhu S, Aslekar A, 2021, Entertainment in Era of AI, Big Data \& IoT. In Digital Entertainment. Palgrave Macmillan, Singapore, 87-109.

[10] Zwitter A, 2014, Big Data Ethics. Big Data \& Society, 1(2): 2053951714559253.

[11] Zheng S, Long F, Fan CC, et al., 2009, Urban Cillages in China: A 2008 Survey of Migrant Settlements in Beijing. Eurasian Geography and Economics, 50(4): 425-446.

[12] Herschel R, Miori VM, 2017. Ethics \& big data. Technology in Society, 49: 31-36.

[13] Dionisio JDN III, Gilbert R, 2013, 3D Virtual Worlds and the Metaverse: Current Status and Future Possibilities. ACM Computing Surveys (CSUR), 45(3): 1-38.

[14] Ludlow P, Wallace M, 2007, The Second Life Herald: The Virtual Tabloid that Witnessed the Dawn of the Metaverse. MIT Press.

[15] Jurkiewicz CL, 2018, Big Data, Big Concerns: Ethics in the Digital Age, Public Integrity, 20(sup1), S46-S59.

[16] Smart JM, Cascio J, Paffendorf J, 2007, Metaverse Roadmap Overview, Accelerated Studies Foundation. Retrieved 2010-09-23. 